\title{
The High-Pressure Segmented Quadrupole Collision Cell (HP-SQCC) as an Ion Molecule Reactor
}

\author{
Yuzhu Guo and K.W. Michael Siu \\ Department of Chemistry and Centre for Research in Mass Spectrometry, York University, Toronto, \\ Ontario, Canada
}

\author{
Vladimir I. Baranov \\ MDS SCIEX, Concord, Ontario, Canada
}

A high-pressure 20-segment quadrupole collision cell (HP-SQCC), which replaces a collision cell in a modified triple-quadrupole mass spectrometer is investigated in this work as an ion-molecule reactor with an inherent heat source. The highest working pressure achievable is $20 \mathrm{mTorr}$. The 20 quadrupole segments permit superimposition of linear axial electric field over the conventional quadrupole field in the radial direction. The axial and radial fields are employed to control ion temperature. Heat is transferred to the reactants through ion frictional heating. The HP-SQCC utilizes a combination of several physicochemical phenomena and an attempt is made to examine a range of ion-molecule reactions. Due to a sufficiently large number of reactive collisions, the reactor is used to promote sequential exothermic ion-molecule reactions. To characterize the performance of the HP-SQCC, the various ion-molecule reactions between the fragment ions of ferrocene $\left(\mathrm{Cp}_{2} \mathrm{Fe}\right)$, cobaltocene $\left(\mathrm{Cp}_{2} \mathrm{Co}\right)$ and nitrogen, oxygen, water and carbon monoxide are investigated. (J Am Soc Mass Spectrom 2005, 16, 957-966) (c) 2005 American Society for Mass Spectrometry

$\mathrm{I}$ on-molecule reactions have captured the fascination of mass spectrometrists for a number of decades and have been probed using a variety of instrumentation, including Fourier-transform ion cyclotron resonance spectrometry, ion-trap mass spectrometry, triplequadrupole mass spectrometry and the selected-ion flow tube technique [1]. The conventional triplequadrupole mass spectrometer is a less than perfect instrument for an examination of ion-molecule reactions due to the relatively low pressure achievable in its second quadrupole $\left(Q_{2}\right)$, which restricts the number of ion-molecule collisions, and to the limited control of ion energy within $\mathrm{Q}_{2}$. Nevertheless, reactions that lead to novel products have been discovered; one such reaction is the ligand-exchange reaction between $\left[\mathrm{Pb}\left(\mathrm{CH}_{3} \mathrm{CN}\right)\right]^{2+}$ and water to give $\left[\mathrm{Pb}\left(\mathrm{H}_{2} \mathrm{O}\right)\right]^{2+}$ and acetonitrile [2]. This was the first observation of $\left[\mathrm{Pb}\left(\mathrm{H}_{2} \mathrm{O}\right)\right]^{2+} ; \mathrm{Pb}^{2+}$ had previously been described as to be among "a select group of doubly charged metal ions that will not form stable complexes in the gas phase with water" [3].

Here we report the first ion-molecule reaction results obtained on a high-pressure 20-segment quadrupole collision cell (HP-SQCC) that functions as the $\mathrm{Q}_{2}$ in a modified triple-quadrupole mass spectrometer. The

Published online April 26, 2005

Address reprint requests to Vladimir I. Baranov, 71 Four Valley Drive, Concord, Ontario, L4K 4V8, Canada. E-mail: vladimir.baranov@sciex.com. highest working pressure achievable is 20 mTorr with neon, about 4 times higher than that achievable on a standard triple-quadrupole instrument. The 20 quadrupole segments permit superimposition of an axial electric field, typically linear, over the conventional quadrupole field in the radial direction [4-6]. The HP-SQCC was originally developed for ion-mobility measurements [5, 7], where the goal is to maintain the drift field low enough that the ion temperature is not increased significantly. In this study, we are exploring the use of the HP-SQCC as an efficient apparatus for utilizing ion-molecule reactions as an analytical method. The axial and radial fields are employed to control the ion temperature.

To characterize the performance of the HP-SQCC, we have elected to use as probes the various ionmolecule reactions between the fragment ions of ferrocene $\left(\mathrm{Cp}_{2} \mathrm{Fe}\right)$ as well as cobaltocene $\left(\mathrm{Cp}_{2} \mathrm{Co}\right)$ and neutrals such as nitrogen, oxygen, water and carbon monoxide. These systems have been much studied [8-13] and will serve well as probes for evaluating the HP-SQCC.

\section{Experimental}

A high-pressure 20-segment quadrupole collision cell (HP-SQCC) was used in this work as an ion molecule reactor, which was installed on a PE SCIEX API 365 triple quadrupole mass spectrometer (Concord, Canada), re- 


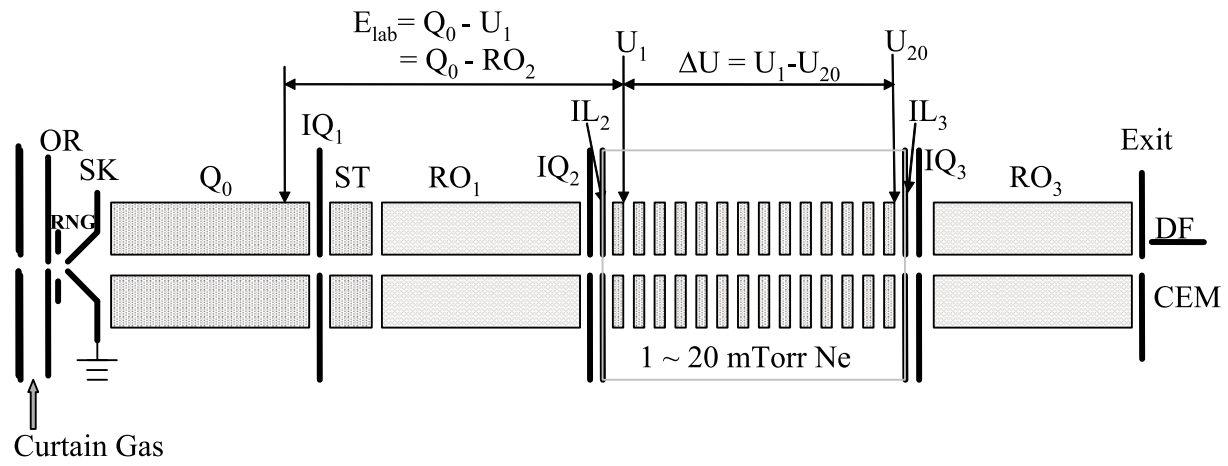

Figure 1. Schematics representation of the experimental setup: $\mathrm{Q}_{0}$ : RF-only ion guide (-7V normally); $\mathrm{RO}_{1}$ and $\mathrm{RO}_{3}$ : DC offset of quadrupole mass analyzers (normally $\mathrm{RO}_{1}=-8.4 \mathrm{~V}, \mathrm{RO}_{3}=\mathrm{U}_{20}-5 \mathrm{~V}$ for MS/MS scan); $\mathrm{IQ}_{1}, \mathrm{IQ}_{2}$ and $\mathrm{IQ}_{3}$ : electrostatic lenses $\left(\mathrm{IQ}_{1}=-7.5 \mathrm{~V}, \mathrm{IQ}_{2}=-27 \mathrm{~V}\right.$ and $\left.\mathrm{IQ}_{3}=\mathrm{U}_{20}-5 \mathrm{~V}\right) ; \mathrm{IL}_{2}, \mathrm{IL}_{3}$ : additional HP-SQCC enclosure lenses $\left(\mathrm{IL}_{2}=-7 \mathrm{~V} ; \mathrm{IL}_{3}=\mathrm{U}_{20}-5 \mathrm{~V}\right)$; ST: short RF-only prefilter $(-7 \mathrm{~V}) ; \mathrm{E}_{\text {lab }}$ : ion energy defined in lab frame; $\mathrm{RO}_{2}$ : DC offset of HP-SQCC (-7V); $\Delta \mathrm{U}$ : DC potential between the first and last segments equally distributed along 20 segments; $U_{1}, U_{20}$ : DC offset of the first and last segment $\left(U_{1}=R_{2}\right.$ $\left.=-7 \mathrm{~V} ; \mathrm{U}_{20}=\mathrm{U}_{1}-\Delta \mathrm{U}\right)$.

placing the original $\mathrm{Q}_{2}$ collision cell (see Figure 1). The radio-frequency (RF-only) segmented quadrupole has been described elsewhere [5, 7]. Briefly, the HP-SQCC was enclosed by two extra lenses, $\mathrm{IL}_{2}$ and $\mathrm{IL}_{3}$, and could be pressurized up to 20 mTorr with Ne. An additional Leybold TW250 turbo pump (Concord, Germany) was employed to evacuate the main vacuum chamber to preserve optimum operational pressure in the $Q_{3}$ region. The reagent gas was directly introduced into the cell through a high-vacuum needle valve. The pressure inside the HP-SQCC was measured directly using an MKS Baratron 627B absolute pressure transducer (Wilmington, MA), with a stated accuracy of $0.25 \%$. The reagent gas was premixed in a home-built gas mixer.

The RF-only quadrupole offset was set at $-7 \mathrm{~V}$. Using a potential divider, an axial drift field, $\Delta \mathrm{U}=\mathrm{U}_{1}-\mathrm{U}_{20}$, was applied axially across the reaction cell $\left(\mathrm{U}_{1}\right.$ was set equal to $\mathrm{RO}_{2}$ ). A standard API 365 collision cell does not have a drift field nor the lenses $\mathrm{IL}_{2}$ and $\mathrm{IL}_{3}$ that bracket the collision cell; $\mathrm{IQ}_{3}$ and $\mathrm{RO}_{3}$ (the $\mathrm{Q}_{3}$ rod offset voltage) are set normally attractive with respect to the collision cell. In the present modified version, $\mathrm{IL}_{3}, \mathrm{IQ}_{3}$ and $\mathrm{RO}_{3}$ were all referenced to the potential of the last HP-SQCC segment, $\mathrm{U}_{20}$ to keep field the same after ions leave the collision cell. The DC offset on the first segment, $\mathrm{U}_{1}$, was equal to the $\mathrm{RO}_{2}$ (normally $-7 \mathrm{~V}$ ) on a standard instrument. A DC power supply from Spectrum Solutions Inc. (Russellton, $\mathrm{PA})$ was used to provide offset voltages for $\mathrm{IL}_{2}$ and $\mathrm{IL}_{3}$. A Kepco Power Supply (Flushing, NY) supplies the floating $\Delta \mathrm{U}$.

As in a standard instrument, each segment of the HP-SQCC was capacitively coupled to $\mathrm{Q}_{3}$. The quadrupole field was decoupled from the axial field in this configuration and assured high ion transmission because of its strong focusing effect $[5,7]$.

Ion-molecule reactions were monitored in the product ion scan mode. $Q_{1}$ was set to mass-select the reagent ion for reaction in the HP-SQCC. The initial energy of the reagent ion was kept as low as possible by adjusting the $E_{\text {lab }}$, defined as $Q_{0}-U_{1}$, to $0 \mathrm{~V} . \mathrm{Q}_{3}$ was used to monitor the unreacted precursor and all product ions. The HP-SQCC could be operated as a standard collision cell by assigning appropriate voltages on $\mathrm{IL}_{2}$ and $\mathrm{IL}_{3}$ (equal to $\mathrm{IQ}_{2}$ and $\mathrm{IQ}_{3}$, respectively), and setting $\Delta \mathrm{U}=0$.

The translational energy for ions exiting HP-SQCC was estimated by biasing $\mathrm{Q}_{3}$ offset relative to the last segment $\mathrm{U}_{20}$ offset. If $\mathrm{Q}_{3}$ offset voltage $\left(\mathrm{RO}_{3}\right)$ is higher than that of $\mathrm{U}_{20}$, a barrier is formed between $\mathrm{Q}_{3}$ and $\mathrm{U}_{20}$. Only ions with translational energy above the barrier can be detected downstream by CEM. The barrier height versus ion current diagram (stopping curve) was used to evaluate ions' translational energy and its distribution.

\section{Materials}

Ferrocene and cobaltocene $\left(\mathrm{Cp}_{2} \mathrm{Fe}\right.$ and $\left.\mathrm{Cp}_{2} \mathrm{Co}\right)$ were purchased from Sigma-Aldrich (St. Louis, MO). One mM stock solution of these compounds were prepared by dissolving the required amounts of solid in methanol. Working solutions were $100 \mu \mathrm{M}$ in $1 / 1$ methanol/acetonitrile. Sample solutions were electrosprayed at a flow rate of $2 \mu \mathrm{L} / \mathrm{min}$. Ultra High-Purity neon was purchased from Praxair (Danbury, CT). High-purity CO was purchased from BOC Canada (Mississauga, Canada).

\section{Results and Discussion}

\section{Influence of the RF Field on the Ion Energy}

The average the radial ion energy $\mathrm{E}_{r}$ in the presence of the RF field can be expressed as follows [14, 15]:

$$
\begin{aligned}
& E_{x}=\frac{m \omega^{2} x^{2}}{8} v_{21}^{2}(a, q)+\frac{m}{4 \gamma_{\perp}^{2}} v_{22}^{2}(a, q), \\
& E_{y}=\frac{m \omega^{2} y^{2}}{8} v_{21}^{2}(-a,-q)+\frac{m}{4 \gamma_{\perp}^{2}} v_{22}^{2}(-a,-q), \\
& E r=E_{x}+E_{y} .
\end{aligned}
$$

Here, $r^{2}=x^{2}+y^{2}$ represents radial location of an ion in 
the RF driven quadrupole field, which is a combination of two terms: spatial $(U)$ and periodic $(V)$ trapping potentials. The dimensionless parameters $\frac{4 e U}{m \omega^{2} r_{0}^{2}}=a$, $\frac{2 \mathrm{eV}}{m \omega^{2} r_{0}^{2}}=q$ were also introduced, where $\mathrm{r}_{0}$ is the electrode separation (inscribed radius), $\Omega$ is the main trapping RF angular frequency for an ion with mass $m$ and charge $e$. The most probable ion thermal speed $\frac{1}{\gamma_{\perp}}$ is related to the translational kinetic temperature $T_{\perp}$ in the radial direction as follows:

$$
\gamma_{\perp}=\frac{1}{\sqrt{2 R T_{\perp}}} ; \quad R=k_{B} / m
$$

Here, $\mathrm{k}_{B}$ is Boltzmann's constant. Two dimensionless parameters $v_{21}^{2}(a, q)$ and $v_{22}^{2}(a, q)$ depend only on the field properties and their values were tabulated in [14, 15].

In our configuration of the experimental setup (see Figure 1), the HP-SQCC is capacitively coupled to $Q_{3}$, which divides the RF voltage by a factor 1.75 , effectively placing the ion selected by $\mathrm{Q}_{3}(a=0.236994, q=$ $0.705996)$ into "the RF-only" ion guide stability condition $(a=0, q=0.4)$. In this case, eq 1 can be simplified to:

$$
E_{r}=\frac{m \omega^{2} r_{i}^{2}}{8} v_{21}^{2}(0, q)+\frac{m}{2 \gamma_{\perp}^{2}} v_{22}^{2}(0, q)
$$

because $v_{21}^{2}(0, q)=v_{21}^{2}(0,-q)$ and $v_{22}^{2}(0, q)=v_{22}^{2}(0,-q)$. Let us consider the iron cyclopentadienyl ion's $\left(\mathrm{CpFe}^{+}, \mathrm{m} / \mathrm{z}\right.$ $=121$ ) reaction with CO. As was observed previously [16, 17] and confirmed in this work, $\mathrm{CpFe}^{+}$reacts with $\mathrm{CO}$ sequentially:

$$
\mathrm{CpFe}(\mathrm{CO})_{\mathrm{n}}^{+}+\mathrm{CO} \rightarrow \mathrm{CpFe}(\mathrm{CO})_{\mathrm{n}+1}^{+}
$$

where $\mathrm{n}=0,1,2$.

Under typical conditions of our experiment, dependence of the averaged radial ion energy versus its position $\left(\mathrm{r}_{o}, q\right)$ in the RF field is presented in Figure 2. Highest averaged radial ion energy is observed in vicinity of the stability boundaries [4] and close to $r_{o}$. Assuming that $Q_{3}$ is adjusted to pass the third $C O$ cluster, $\mathrm{CpFe}(\mathrm{CO})_{3}{ }^{+}$, in the HP-SQCC the stability parameters for this ion are $a=0, q=0.4$. Simultaneously, the precursor ion, the first and the second clusters are under the conditions of $q=0.678,0.55$, and 0.463, respectively $\left(a=0\right.$ for all ions in $\left.Q_{2}\right)$. Because of sequential character of this ion molecule reaction, all ions should be considered, not only immediate precursor. Collisions with reaction/collision gas (reactive as well as non-reactive collisions) lead to some energy transfer between the axial and radial translational degrees of freedom [18]. It is expected that collisions
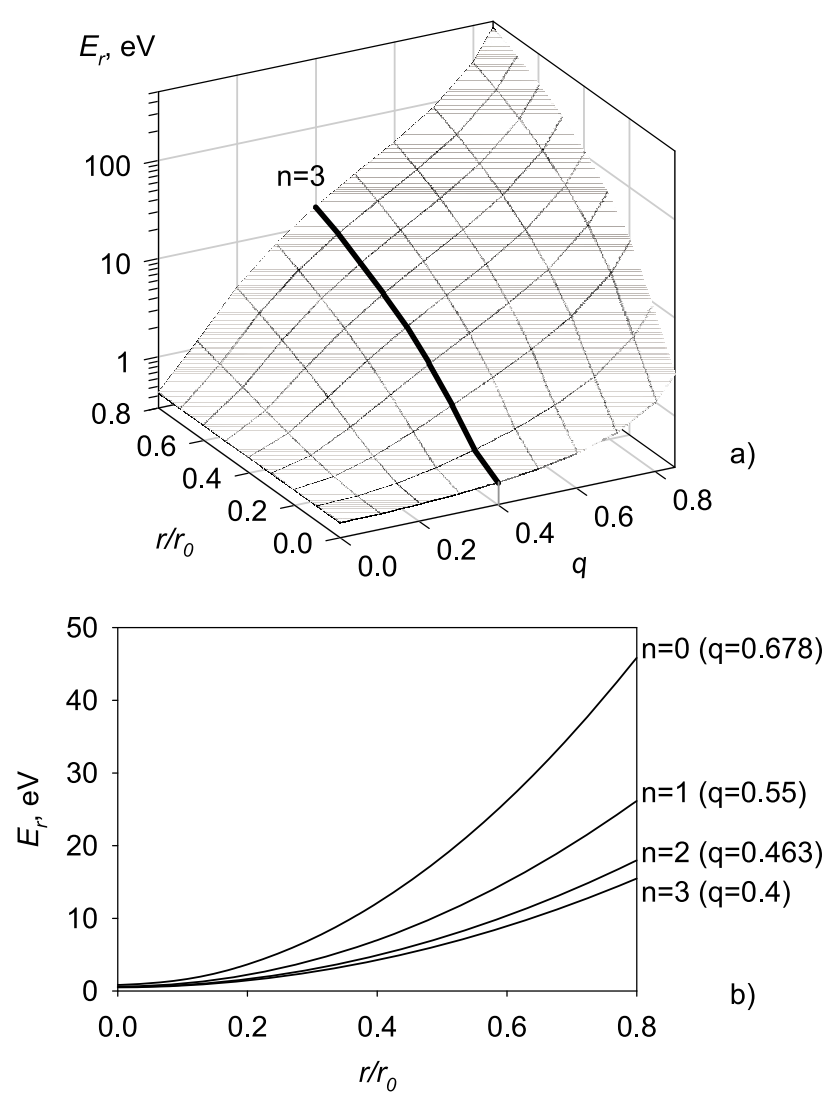

Figure 2. (a) Average radial ion energy in the quadrupole RF field versus $q$ parameter and radial position $r / r_{o}$. $\mathrm{n}$ is the number of $\mathrm{CO}$ molecules in the $\mathrm{CpFe}(\mathrm{CO})_{n}{ }^{+}$cluster. The following parameters were used in the calculations: $\Omega=5.1 \mathrm{Mrad} / \mathrm{s}, \frac{1}{\gamma_{\perp}}=828.9$ $\mathrm{m} / \mathrm{s}$ and $r_{o}=4.1 \mathrm{~mm}$. The overall structure for the dependence of the ion radial energy from the $q$ parameter is somewhat expected: the field contribution increases with increasing distance from the quadrupole axis and increasing $q$ value. (b) Average radial ion energy as a function of the ion radial position in the HP-SQCC quadrupole field for simultaneously present products in Reaction 4 . $Q_{3}$ is adjusted to pass the third cluster.

should result in a collapse of the ion beam around the cell's axis $[19,20]$. In this case, the potential energy portion of the average radial ion energy $\left(\frac{m \omega^{2} r_{i}^{2}}{8} v_{21}^{2}(0, \mathrm{q})\right.$, see eq 3) is negligible. However, the kinetic energy portion $\left(\frac{m}{2 \gamma_{\perp}^{2}} v_{22}^{2}(0, q)\right)$ will not diminish. As can be seen in Figure $2 b$, in the vicinity of the central axis, where the strength of the RF field is minimal, the RF field contribution to the average energy is also minimal. In the presence of collisions, the radial and axial degrees of freedom cannot be considered as independent. Under usual experimental conditions, the initial axial translational energy is higher than the radial one due to the collimation of the ion beam in $\mathrm{Q}_{0}$. However, the temperatures of all translational degrees of freedom might be the same. Collisions with a target gas lead initially to energy transfer from the axial to the radial direction that follows by thermal equilibration. After thermal 
equilibration the RF field's contribution to ion frictional heating is equally distributed among all translational degrees of freedom.

The axial drift field $\Delta U$ results in some increase of the ion beam's cross-section (due to the collisional energy transfer from axial to radial direction) as well as in increase of the ion axial temperature, thus contributing also to both components of the radial ion energy through collisions with target gas. Therefore, the axial field's contribution to the enthalpy of the ion-molecule reaction is direct as well as indirect by increase of the RF-field input.

\section{Influence of the Axial Drift Field on the Ion Energy}

The axial field affects ion-molecule reactions through change of the reaction time and contribution to the enthalpy of reaction. The collisions between the ion and the neutrals have been viewed as a "slow" heating event [21]. The effects of an axial drift field in a segmented quadrupole have been described in detail [22]. The residence time of the ions under a given field strength within the low-field limit are described by the ions' mobilities that are related to the ions' orientationaveraged collision cross-sections [23]. Collisions limit the drift velocities and direct some of the drift energy into heat contributing to the enthalpy of reaction. The frictional ion heating rate $\mathrm{Q}_{i}$ is:

$$
Q_{i}=\mathrm{n} \mu \nu v_{D}^{2}
$$

where $\mathrm{n}$ is the ion number density, $\mu$ is the reduced mass, $\nu$ is the collisional frequency, and $v_{D}$ is the ion drift velocity. If thermodynamic equilibrium is reached with the gas of Maxwellian particles, the frictional ion heating rate is equal to ion cooling rate [24]:

$$
Q=3 k_{B} \frac{n m}{m+m_{n}} \cdot\left(T_{n}-T\right)
$$

where $\mathrm{m}_{n}$ is the collision/reaction gas mass and $\mathrm{T}_{n}$ is its temperature. In this case:

$$
3 k_{B}\left(T_{n}-T\right)=-m_{n} v_{D}^{2}
$$

Because the drift velocity is proportional to $\Delta \mathrm{U} / \mathrm{L}$ ( $\mathrm{L}$ is the HP-SQCC length), the temperature difference is proportional to $(\Delta \mathrm{U} / \mathrm{L})^{2}$. A simple estimation reveals that for a field of $0.5 \mathrm{~V} / \mathrm{cm}$, the ion temperature could reach several thousand degrees, which might significantly contribute to the enthalpy of the ion-molecule reaction or can lead to thermal dissociation of the drifting ions. However, drift velocity is inversely proportional to the collision/reaction gas number density. Thermodynamic equilibrium can be reached only under certain experimental conditions; the unfavorable combination of short ion residence time for high axial drift

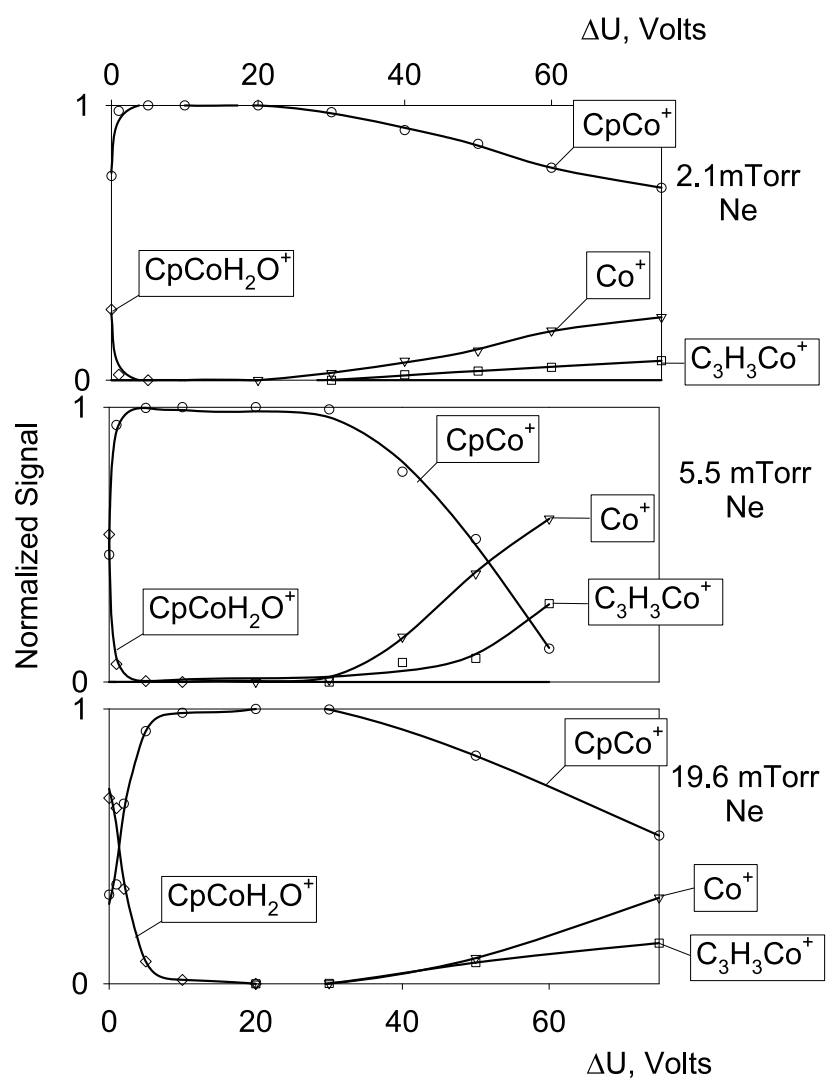

Figure 3. Thermal dissociation of the $\mathrm{CpCo}^{+}$ion due to frictional ion heating: dependence of normalized ion intensities versus drift field, $\Delta \mathrm{U}$, and Ne collision gas pressure. Signal normalization was conducted on the sum of all ion intensities. Water adducts were formed from residual water vapor as a result of association reaction. The $\mathrm{CpCo}^{+}$ion was mass-selected by $\mathrm{Q}_{1}$.

fields and low gas number density reduces frictional ion heating. Therefore, one should expect that the efficiency of thermal dissociation should be low for low gas pressure, it should increase under intermediate pressures and should decrease again for high pressure. This trend was observed experimentally in the case of $\mathrm{CpCo}^{+}$ions colliding with $\mathrm{Ne}$ in the presence of the drift field (see Figure 3). Two dissociation channels are apparent:

$$
\begin{aligned}
\mathrm{CpCo}^{+} & \rightarrow \mathrm{Co}^{+} \\
& \rightarrow \mathrm{C}_{3} \mathrm{H}_{3} \mathrm{Co}^{+},
\end{aligned}
$$

These products are detected under all three Ne pressures (2.1, 5.5 and 19.6 mTorr). However, the most efficient dissociations are observed around 5.5 mTorr where the ion cooling rate is not sufficient to prevent dissociation and the ion residence time is not sufficiently short to reduce resultant heating. In this experiment, $\mathrm{Q}_{1}$ was adjusted for $\mathrm{CpCo}^{+}$; the RF field coupled to $\mathrm{Q}_{3}$ additionally contributed to the ion frictional heating in the radial direction. When $\mathrm{Q}_{3}$ is adjusted for $\mathrm{Co}^{+}$, the precursor $\mathrm{CpCo}^{+}$ion is in the RF field characterized by $q=0.19$. For this $q$ value, $v_{21}^{2}(0,1.19)=$ 
0.0378 and $v_{22}^{2}(0,0.19)=1.035$, which for $\mathrm{r}_{o}=0.1 r$ and $T_{\perp}=500 \mathrm{~K}$ corresponds to $\mathrm{E}_{r}=0.071 \mathrm{eV}$, rather insignificant in comparison to the axial drift field's contribution. It is interesting to note that the water cluster $\mathrm{CpCoH}_{2} \mathrm{O}^{+}$, an electrostaticaly-bonded complex, produced as a result of residual water vapor in neon is expected to be less stable than $\mathrm{CpCo}^{+}$or $\mathrm{C}_{3} \mathrm{H}_{3} \mathrm{Co}^{+}$. When $\mathrm{Q}_{3}$ is adjusted to pass $\mathrm{CpCo}\left(\mathrm{H}_{2} \mathrm{O}\right)^{+}$, the precursor $\mathrm{CpCo}^{+}$ion is in the RF field characterized by $q=0.458$. For this $q$ value $v_{21}^{2}(0,0.458)=0.028$ and $v_{22}^{2}(0,0.458)=1.25$, which for $\mathrm{r}_{o}=0.1 r$ and $T_{\perp}=500 \mathrm{~K}$ corresponds to $\mathrm{E}_{r}=0.25 \mathrm{eV}(0.035 \mathrm{eV}$ in the center-ofmass coordinates). However, as can be seen in Figure 3, even this condition is not sufficiently energetic to prevent complexation with water without the help of the axial drift field.

\section{Investigation on the Ion Translational Energy Upon Exiting the HP-SQCC with a $Q_{3}$ Offset}

This section dwells on the translational energy of ions exiting the HP-SQCC as measured using different $Q_{3}$ offsets. It is well known that the quadrupole rod offset is far from being an ideal energy barrier [25]. For example, it would be beneficial to install a three-grid energy analyzer between the cell and $Q_{3}$. Such an arrangement will facilitate more precise measurements of the ion energy by employing a repulsive electrostatic field that is spatially uniform. Additionally, a wellcharacterized reaction/collision gas flow controlling system similar to that described in references $[26,27]$ is bound to improve the reproducibility of reaction profiles and minimize occurrence of unwanted reactions from impurities. Although these and additional improvements seem reasonable, they could hardly be expected to be implemented in practical (easy-to-use) analytical instrumentation. The goal of this paper is to characterize the HP-SQCC as an ion-molecule reactor in its simplest configuration. This same reason compels us to defer intriguing ion drift studies $[5,7,23]$ involving reactive mixtures for future investigations.

Despite limited capabilities of $\mathrm{Q}_{3}$ as an energy analyzer, change the $\mathrm{Q}_{3}$ offsets offers valuable insight into ion relaxation processes [28, 29] which are discussed here. Typical stopping curves (graphs of ion intensities versus the $\mathrm{Q}_{3}$ offsets) for constant $\mathrm{Co}^{+}$and $\mathrm{Cp}_{2} \mathrm{Co}^{+}$ion beams are presented in Figure 4 and Figure 5, respectively. These ions were produced from $\mathrm{Cp}_{2} \mathrm{Co}$ and mass-selected by $\mathrm{Q}_{1}$; they traversed the HP-SQCC filled with $\mathrm{Ne}$ and overcame the $\mathrm{Q}_{3}$ offset barrier for detection. The stopping curve is characteristic of the integral distribution of the axial ion energy: only ions with axial energy above the $\mathrm{Q}_{3}$ offset can be successfully detected. More accurately, the detector registers only ions that passed $\mathrm{Q}_{3}$. It has been described previously (references [30-32], for example), that ion transmission through a quadrupole assembly (which usually includes aperture at exit) depends on the ion beam energy (along with
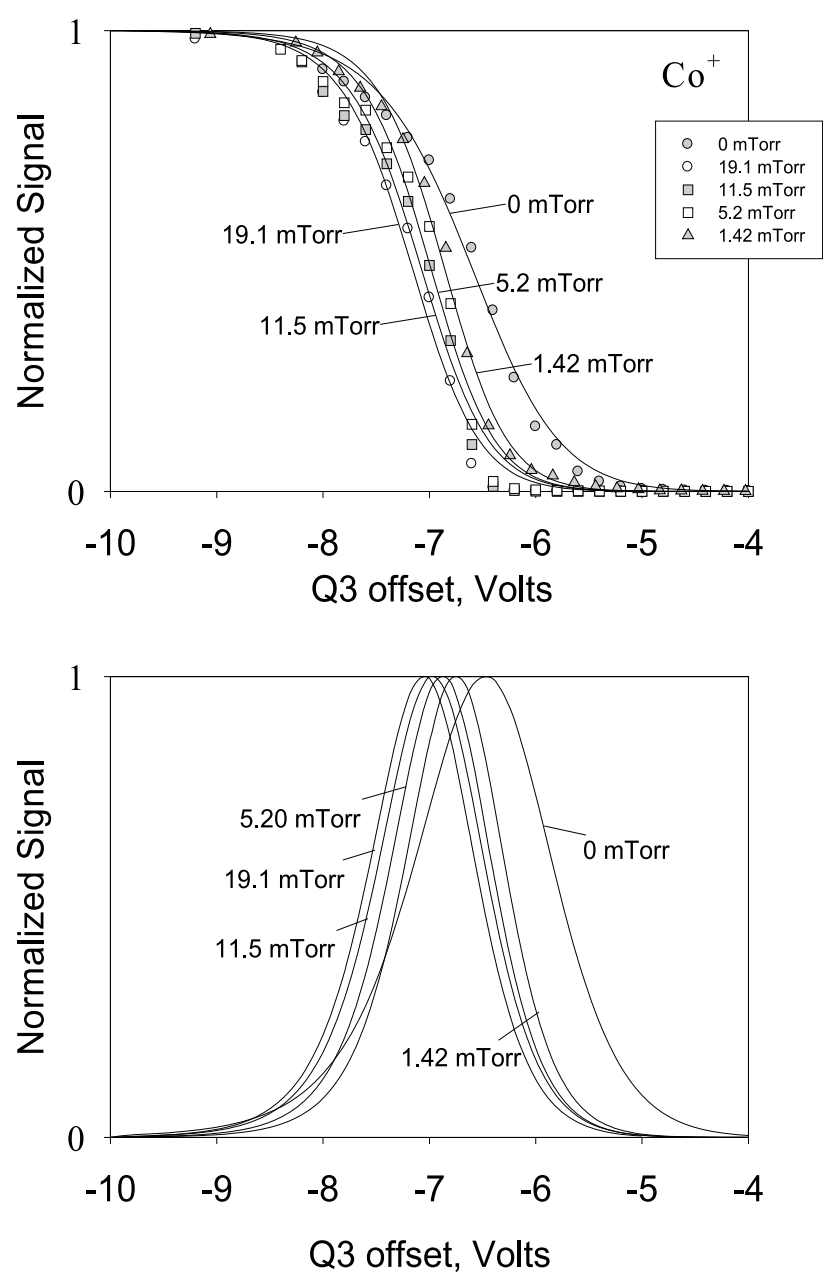

Figure 4. Stopping curves (graphs of ion intensities versus $Q_{3}$ offsets) for the $\mathrm{Co}^{+}$ion beam produced from $\mathrm{Cp}_{2} \mathrm{Co}$ sample. Fitted curves were plotted employing three parameters sigmoid: $y=\frac{a}{1+e^{-\left(\frac{x-x_{0}}{b}\right)}}$, where $y$ is the normalized ion intensity, $x$ is the $Q_{3}$ offset, and $a, b$ and $\mathrm{x}_{0}$ are adjustable parameters. The lower graph shows plots that are the differentials of the fitted curves for $\frac{d}{d x}\left(\frac{a}{1+e^{-\left(\frac{x-x_{0}}{b}\right)}}\right)=\frac{a}{2 b}\left(1+\cosh \left(\frac{x-x_{0}}{b}\right)\right)^{-1}$.

other parameters). An attractive offset leads to periodic focusing of ions (fluctuation of the ion beam intensity) versus their axial energy. Moreover, this effect is mass dependent. As a consequence, resultant stopping curves are not sigmoidal, as one would expect from the integral of the second momentum of normal distribution of the ion axial velocity. Therefore, the stopping curves were subjectively cut somewhere in the attractive part of the $Q_{3}$ offset. This procedure does not affect the position or the width of the distribution on the energy scale. In spite of these reservations, it can be clearly seen that by increasing $\mathrm{Ne}$ pressure, the ion beam's axial energy and its temperature decreases. The fitted curves were drawn employing three parameters sigmoid to make this trend clear.

The practical value of differentiating experimental 

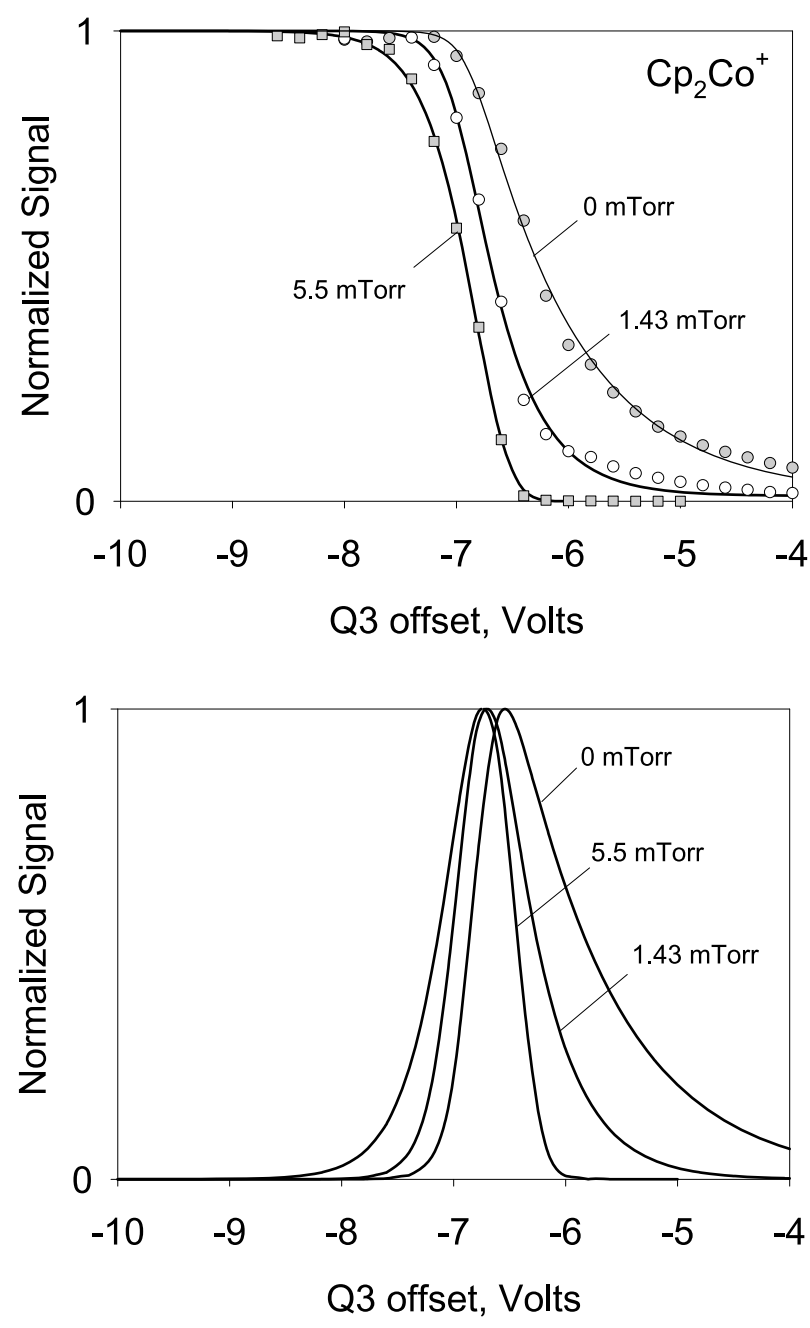

Figure 5. Stopping curves (graphs of ion intensities versus $Q_{3}$ offsets) for the $\mathrm{Cp}_{2} \mathrm{Co}^{+}$ion beam produced from $\mathrm{Cp}_{2} \mathrm{Co}$ sample. Fitted curves were drawn employing three parameters sigmoid (see Figure 4). The lower graph shows plots that are the differentials of the fitted curves.

data is always debatable and this is also true in our case. However, in order to support the semi-quantative nature of our investigation it was found to be beneficial to differentiate fitted curves. Despite its oversimplification, such a procedure provides powerful insight into relaxation processes. As can be seen in Figure 4 and Figure 5, the maximum of the energy distribution shifts from $-6.5 \mathrm{~V}$ to $-7 \mathrm{~V}$ with increasing Ne pressure. The width of the distribution also decreases with increasing Ne pressure due to collisional relaxation of all translational degrees of freedom. Under the conditions of our experiment, the $Q_{0}$ offset is equal to $-7 \mathrm{~V}$; therefore, one can observe that the $\mathrm{Co}^{+}$ions are nearly thermalized with a Ne pressure above $\sim 10$ mTorr. Additionally, according to eq 3 , under thermalized conditions, the ion temperature is expected to be similar in all directions because $v_{22}^{2}(0,0.4)=1.18$ [15] and the RF field contribution should be minimal. This similar trend is also observed in the case of $\mathrm{Cp}_{2} \mathrm{Co}^{+}$ions colliding with $\mathrm{Ne}$
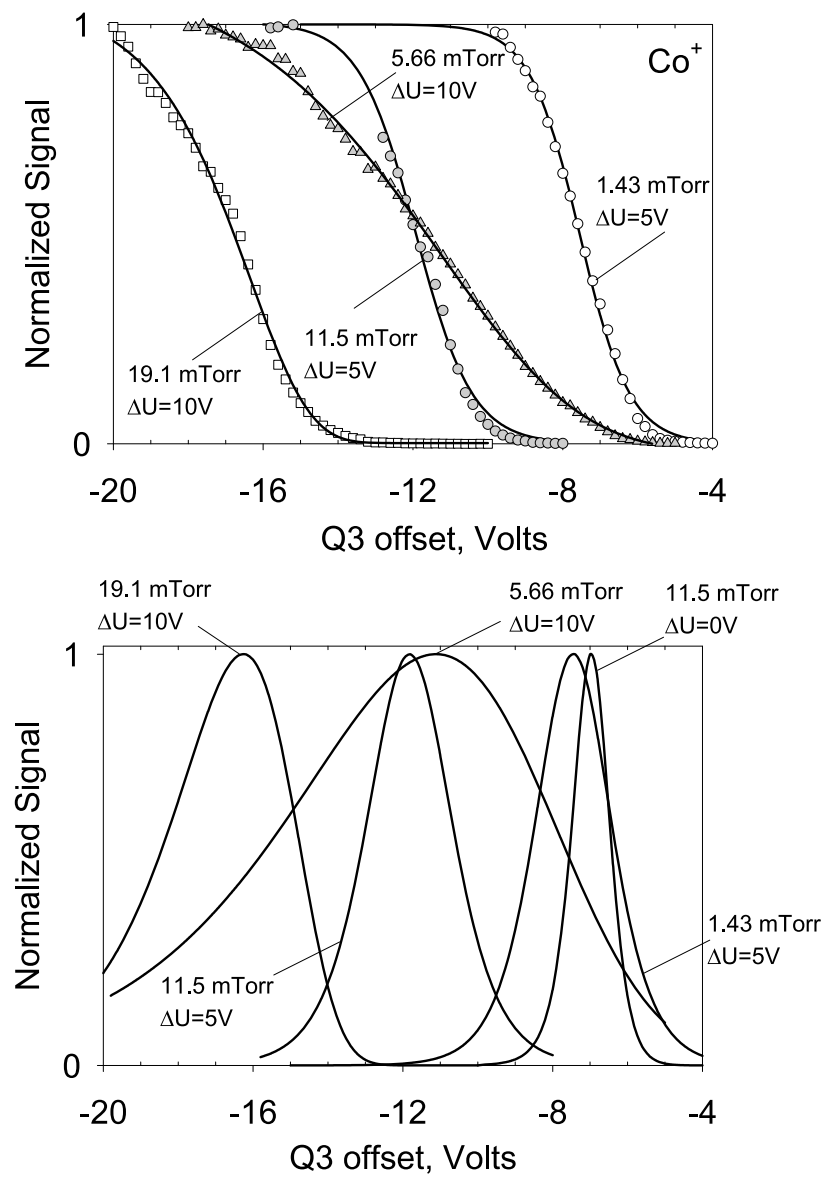

Figure 6. Stopping curves (graphs of ion intensities versus $Q_{3}$ offsets) for the $\mathrm{Co}^{+}$ion beam produced from $\mathrm{Cp}_{2} \mathrm{Co}$ sample under different drift fields, $\Delta \mathrm{U}$. Fitted curves were drawn employing three parameters sigmoid (see Figure 4). The lower graph shows plots that are the differentials of the fitted curves.

(Figure 5). As these ions have a larger cross-section and mass, they collide more often with Ne but require more collisions to dissipate their axial translational energy. However, even in this case, 10 mTorr of Ne is sufficient to achieve reasonable equilibrium among all translational degrees of freedom.

Such near thermalization (although desirable to control the enthalpies of ion molecule reactions) is achievable under our experimental conditions, but should be considered of limited value as it simultaneously involves the loss of directional axial movement. To deliver ions from the entrance to the exit of the HP-SQCC reproducibly (independent of the total ion current and the $Q_{3}$ state), it was found $[5,22,33]$ to be of benefit to utilize the axial drift field. In the presence of the drift field $\Delta \mathrm{U}$, ions collide, drift and are trapped by the RF field simultaneously. The design of the HP-SQCC ensures that, without collisions, the ion energy distribution (axial as well as radial) remains the same before and after the cell. One can also expect that the many collisions in the HP-SQCC under a $\Delta \mathrm{U}$ should shift the laboratory ion energy from its original near $\mathrm{Q}_{0}-\mathrm{RO}_{2}$. Lack of collisional relaxation will further contribute to 

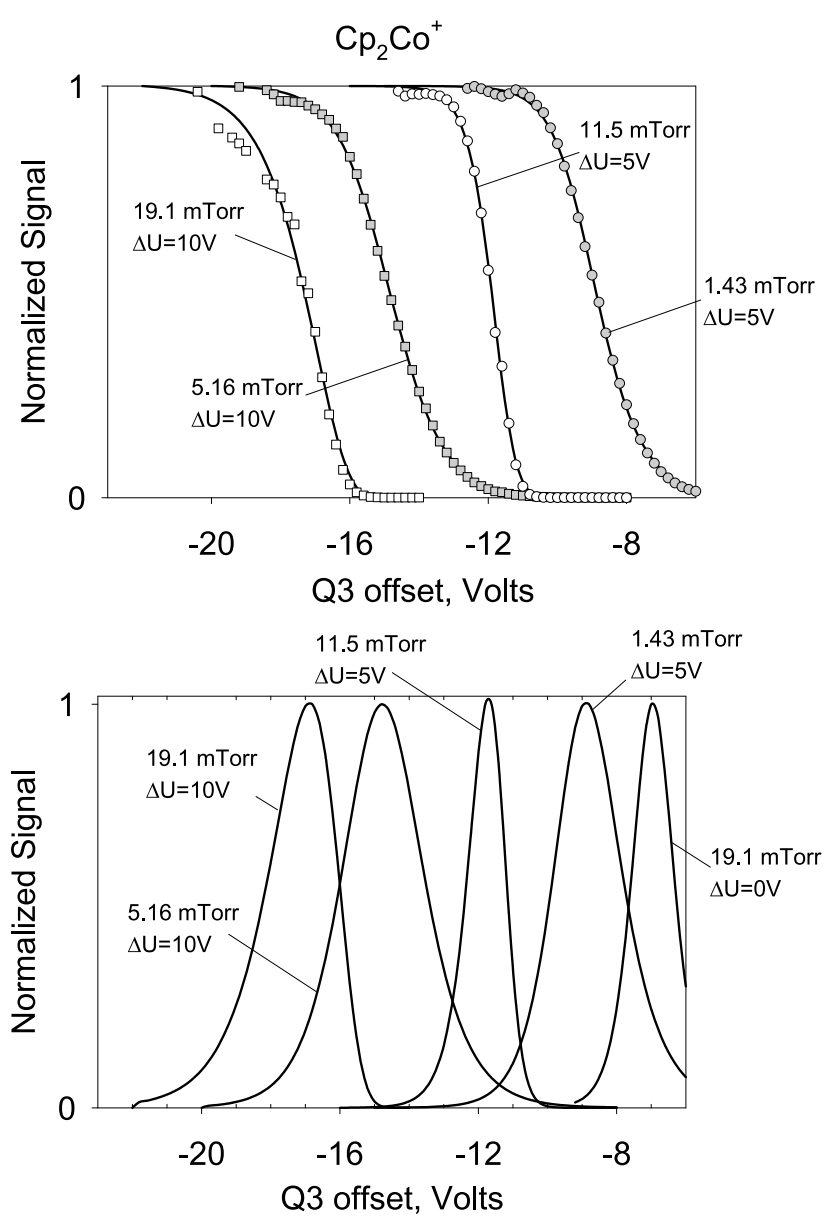

Figure 7. Stopping curves (graphs of ion intensities versus $Q_{3}$ offsets) for the $\mathrm{Cp}_{2} \mathrm{Co}^{+}$ion beam produced from $\mathrm{Cp}_{2} \mathrm{Co}$ sample under different drift fields, $\Delta \mathrm{U}$. Fitted curves were drawn employing three parameters sigmoid (see Figure 4). The lower graph shows plots that are the differentials of the fitted curves.

the laboratory ion energy. It was observed experimentally and is demonstrated in Figure 6 and Figure 7 in the case of $\mathrm{Co}^{+}$and $\mathrm{Cp}_{2} \mathrm{Co}^{+}$ions colliding with Ne. Successful relaxation of the $\mathrm{Cp}_{2} \mathrm{Co}^{+}$ions can be achieved under $11.5 \mathrm{mTorr}$ pressure of $\mathrm{Ne}$ for $\Delta \mathrm{U}=5 \mathrm{~V}$. It is interesting to observe that under intermediate pressure (1.43 mTorr) ions have an elevated temperature in comparison with both "no drift field" (19.1 mTorr, $\Delta \mathrm{U}$ $=0 \mathrm{~V})$ and "drift field, many collisions" (11.5 mTorr, $\Delta \mathrm{U}$ $=5 \mathrm{~V})$ conditions. The same phenomenon was observed for higher drift field $\Delta \mathrm{U}=10 \mathrm{~V}$. Total relaxation of the ion temperature was not observed even under 19.1 mTorr of Ne.

It is also possible to distinguish between exothermic and endothermic reactions by analyzing the differential stopping curves of the product ions. For example, as seen in Figure 8, the differential distribution (and temperature) is narrower for products $\mathrm{CpCoO}_{2}{ }^{+}$of the ligand switching reaction in comparison with the distribution of the reactant (precursor) ions because this reaction occurs only on the "low energy tail" of the precursor ion $\left(\mathrm{CpCoN}_{2}{ }^{+}\right)$energy distribution. This ef-

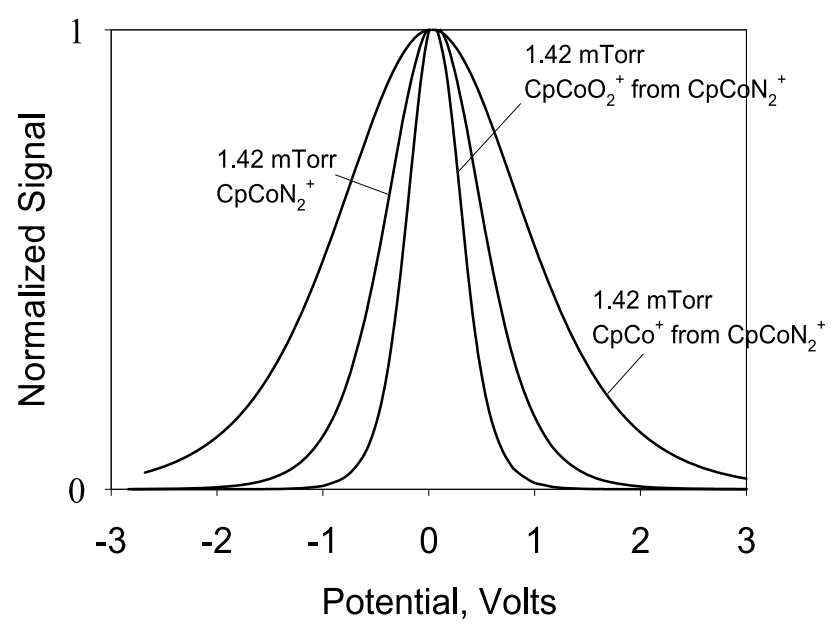

Figure 8. Differential stopping curves of the precursor $\mathrm{Cp}$ $\mathrm{CoN}_{2}{ }^{+}$; the product of ligand switching reaction, $\mathrm{CpCoO}_{2}{ }^{+}$; and the product of thermal dissociation, $\mathrm{CpCo}^{+}$, for the same $\mathrm{Ne}$ pressure of 1.42 mTorr. The curves are normalized and recentered.

fect is related to the anti-Arrhenius dependence of the rate constants of some exothermic reactions on temperature (see below). On the contrary, the product of endothermic dissociation reaction $\mathrm{CpCo}^{+}$is produced from the "high energy tail" of the precursor ion (Cp$\mathrm{CoN}_{2}{ }^{+}$) energy distribution and its distribution is wider than that of the precursor.

\section{Ion Molecule Reactions in the HP-SQCC}

Under mild interface conditions of low orifice voltage $(\mathrm{OR})$, molecular ions of ferrocene and cobaltocene $\mathrm{Cp}_{2} \mathrm{Fe}^{+}$and $\mathrm{Cp}_{2} \mathrm{Co}^{+}$, are observable. Increasing the OR induced the dissociation of these molecular ions and allowed fragment ions and adducts to be seen, which include $\mathrm{CpFe}^{+}$(or $\mathrm{CpCo}^{+}$) and its $\mathrm{H}_{2} \mathrm{O}, \mathrm{O}_{2}, \mathrm{~N}_{2}$ adducts. These adducts formed because $\mathrm{N}_{2}$ and air were used as the curtain and nebulizer gas, respectively.

$\mathrm{CpFe}^{+}$reacts rapidly with $\mathrm{H}_{2} \mathrm{O}$ [16]. Twenty mTorr of neon does not promote Ne adducts, but some water adducts can be observed. Without the collision/reaction gas only parent ions are observed. Unfortunately, the amount of water introduced together with neon cannot be controlled without an exceptional effort. Therefore, in addition to the source, the HP-SQCC can also produce water clusters.

It is important to remember that clusters (for example, $\mathrm{CpCoH}_{2} \mathrm{O}^{+}$, see Figure 3), if they are not selected by $\mathrm{Q}_{1}$ from the source, are formed in the HP-SQCC. We observed that an additional enthalpy provided by the drift or RF field prevents clusters from forming. Therefore, reported data suggests an anti-Arrhenius dependence of the rate constants for the cluster formation on temperature. A decrease of ion-molecule reaction rate with increasing temperature is quite common for exothermic association reactions. As a result, there is a shift of the equilibrium toward the reactants due to a tem- 


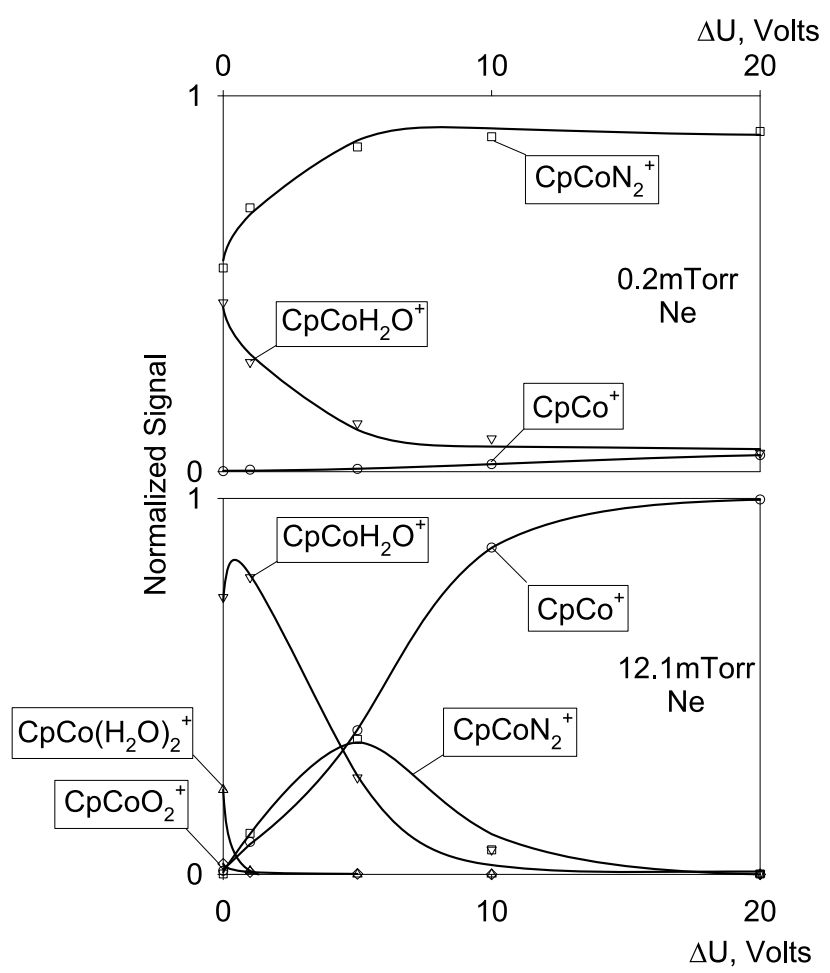

Figure 9. Thermal dissociation of the $\mathrm{CpCoN}_{2}{ }^{+}$ion due to frictional ion heating: dependence of normalized ion intensities versus drift field, $\Delta \mathrm{U}$, and $\mathrm{Ne}$ collision gas pressure. Signal normalization was conducted on the sum of all ion intensities. Water and oxygen adducts were formed from residual gases as a result of cluster-switching reaction. The $\mathrm{CpCoN}_{2}{ }^{+}$ion was massselected by $\mathrm{Q}_{1}$.

perature increase. In special cases, even entropy effects were considered to be responsible for this trend [34]. These effects allow an additional suppression of cluster formation in the HP-SQCC without significant alteration of more exothermic ion molecule reactions.

Alternatively, some clusters of the metallocenes can be obtained from the ion source. For example, $\mathrm{Cp}$ $\mathrm{CoN}_{2}{ }^{+}$cluster forms readily in the ion source employing nitrogen as a curtain gas. This cluster undergoes ligand-switching reactions with water and oxygen, which are present in neon as residual gases (see Figure 9). It was noticed [17, 34] that ions of half-sandwich metallocenes react with electron-donating ligands with rate constants that are inversely proportional to the ligand ionization energies (IEs). In general, bond energies are also inversely proportional to the ligand IEs. Consequently, $\mathrm{N}_{2}(\mathrm{IE}=15.6 \mathrm{eV})$ should be substituted by $\mathrm{H}_{2} \mathrm{O}(\mathrm{IE}=12.6 \mathrm{eV})$ and $\mathrm{O}_{2}(\mathrm{IE}=12.07 \mathrm{eV})$. These reactions were observed in the HP-SQCC and the results are presented in Figure 9. Even under a very low Ne pressure ( $0.2 \mathrm{mTorr})$, frictional ion heating slowed down the ligand-switching reaction and significantly suppressed water-cluster formation under drift fields $\Delta \mathrm{U}>10 \mathrm{~V}$. Under a moderate Ne pressure (12.1 mTorr), the nitrogen cluster fully exchanged with water and oxygen (for $\Delta \mathrm{U}=0 \mathrm{~V}$ ); upon larger $\Delta \mathrm{U}$ values, frictional heating largely suppressed these reactions. In addition,
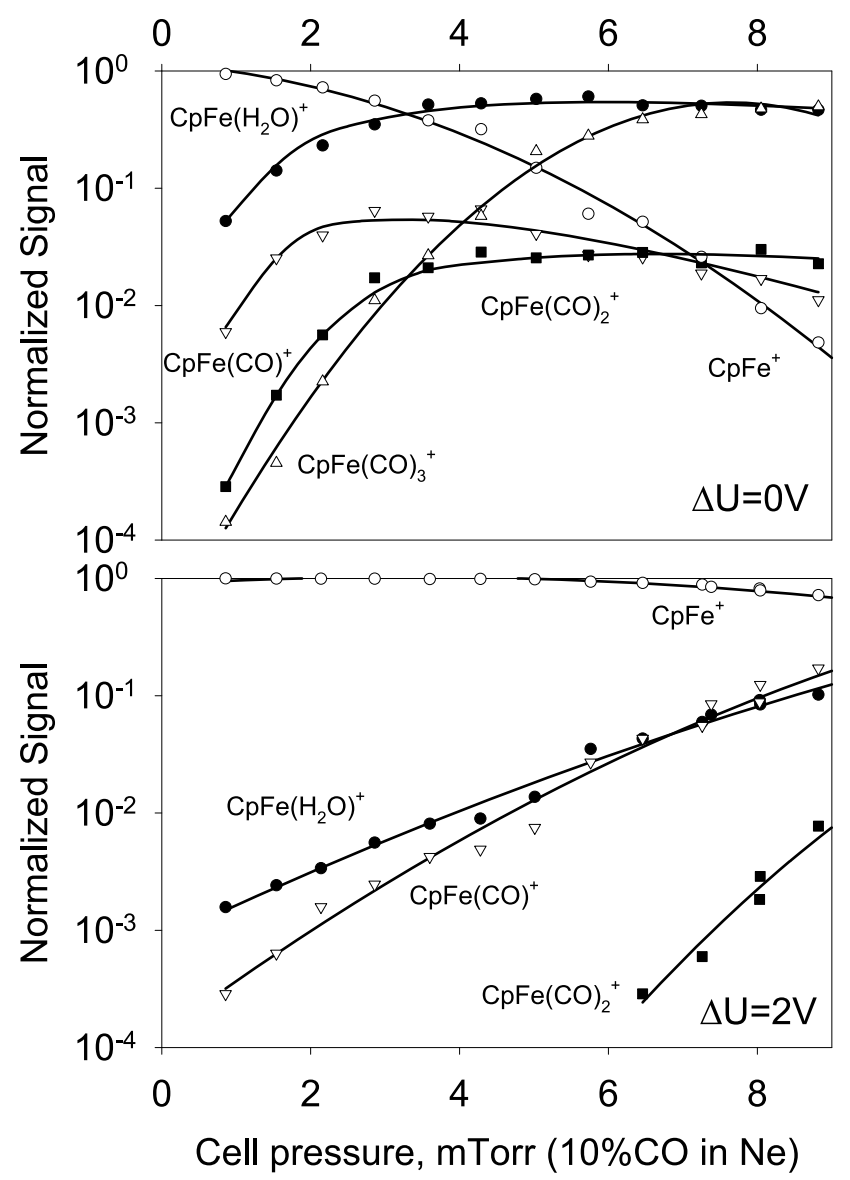

Figure 10. Reactions of $\mathrm{CpFe}^{+}$ions with $\mathrm{CO}$ under different reactant gas pressures $(10 \% \mathrm{CO}$ in $\mathrm{Ne})$ and under two drift field conditions, $\Delta \mathrm{U}=0$ (upper) and $\Delta \mathrm{U}=2 \mathrm{~V}$.

frictional heating also decomposes the nitrogen cluster to $\mathrm{CpCo}^{+}$for $\Delta \mathrm{U} \geq 5 \mathrm{~V}$.

An anti-Arrhenius dependence of the cluster formation rate constant is also apparent in reactions between $\mathrm{CpM}^{+}$and $\mathrm{CO}$, despite the fact that the $\mathrm{CpM}^{+}-\mathrm{CO}$ bond is much stronger than those between $\mathrm{CpM}^{+}$and the aforementioned ligands due to its electron donor-acceptor nature [16]. The $\mathrm{CpFe}^{+}$ion reacts with $\mathrm{CO}$ according to eq 4 (see Figure 10). Even a relatively moderate axial drift field $(\Delta \mathrm{U}=2 \mathrm{~V})$ dramatically slows the ionmolecule reactions down. The results are a combined effect of an anti-Arrhenius dependence of the rate constants and a reduction of the ions' residence times inside the HP-SQCC. The ion's residence time is inversely proportional to $\sqrt{\Delta U}$. Increasing the reactant gas pressure at a $\Delta \mathrm{U}$ of $2 \mathrm{~V}$ results in more abundant complexes, including $\mathrm{CpFe}\left(\mathrm{H}_{2} \mathrm{O}\right)^{+}$. This is a combined effect of increasing ions' residence times and increasing thermalization.

\section{Conclusions}

The results presented here demonstrate that the highpressure segmented quadrupole collision cell is a valuable ion-molecule reactor with an inherent heat source. 
Heat is transferred to the reactants through ion frictional heating. There are two major sources of the ion frictional heating under typical HP-SQCC conditions: the radial RF-trapping field and the axial drift field. Both sources are closely interconnected. The contribution from the trapping field depends on the radial position of the colliding ions. The axial drift field results in an increase of the ion axial temperature. However, collisions with the target gas lead to an increase of the ion beam cross-section thus contributing to radial heating. Therefore, the axial drift field contributes directly to the enthalpy of the ion-molecule reaction as well as indirectly by increasing the RF field input. The HPSQCC utilizes a combination of several physicochemical phenomena and permits examination of a range of ion-molecule reactions. In the future, it would be interesting to see if it can be used to promote selected endothermic reactions (via frictional heating) as well as to suppress unwanted reactions with impurities. In addition, the same reactor can be used to promote sequential exothermic ion-molecule reactions provided there are sufficiently large numbers of collisions and sufficiently long ion residence times.

\section{Acknowledgments}

The authors thank Drs. Ghlomreza Javahery and Yun Ling for their input in designing and building the HP-SQCC, and in modifying the API 365 mass spectrometer. They also thank Drs. Bruce Thomson and Sheldon M. Williams for fruitful discussion of our results. Financial support from the Natural Sciences and Engineering Research Council (NSERC) of Canada, MDS Sciex and York University is gratefully acknowledged.

\section{References}

1. Armentrout, P. B. Theory and Ion Chemistry. In The Encyclopedia of Mass Spectrometry, Vol. 1, Gross, M. L.; Caprioli, R., eds. Elsevier: Amsterdam, 2003.

2. Shi, T.; Orlova, G.; Guo, J.; Bohme, D. K.; Hopkinson, A. C.; Siu, K. W. M. Existence of doubly charged lead monohydrate: Experimental evidence and theoretical examination. J. Am. Chem. Soc. 2004, 126, 7975-7980.

3. Stace, A. J. Metal ion solvation in the gas phase: the quest for higher oxidation states. J. Phys. Chem. A 2002, 106, 7993-8005.

4. Dodonov, A. F.; Kozlovski, V. I.; Loboda, A. V.; Raznikov, V.; Sulimenkov, I. V.; Tolmachev, A. V.; Kraft, A.; Wollnik, H. A new technique for decomposition of selected ions in molecule ion reactor coupled with Ortho-Time-of-Flight mass spectrometry. Rapid Commun. Mass Spectrom 1997, 11 1649-1656.

5. Javahery, G.; Thomson, B. A segmented radiofrequency-only quadrupole collision cell for measurements of ion collision cross section on a triple quadrupole mass spectrometer. J. Am. Soc. Mass Spectrom. 1997, 8, 697-702.

6. Loboda, A. V.; Kozlovski, V. I.; Chardakova, E. V.; Tolmachev, A. V.; Sulimenkov, I. V.; Dodonov, A. F.; Wollnik, H. New method for ion mobility determination by stability threshold measurement in gas filled radio frequency quadrupoles. Rapid Commun. Mass Spectrom. 1998, 12, 45-49.

7. Guo, Y.; Rodriquez, C. F.; Wang, J.; Ling, Y.; Hopkinson, A. C., and Siu, K. W. M. Ion mobility measurements in neon in a modified triple-quadrupole mass spectrometer with a seg- mented $\mathrm{Q}_{2}$. Proceedings of the 50th American Society for Mass Spectrometry Conference; Orlando, FL, June, 2002.

8. Foster, M. S.; Beauchamp, J. L. Ion-Molecule Reactions and Gas-Phase Basicity of Ferrocene. J. Am. Chem. Soc. 1975, 97, 4814-4817.

9. Corderman, R. R.; Beauchamp, J. L. Ion Cyclotron Resonance Investigations of Alkylation of $\left(\eta^{5}-\mathrm{C}_{5} \mathrm{H}_{5}\right) \mathrm{Ni}^{+}$and $\left(\eta^{5}-\right.$ $\left.\mathrm{C}_{5} \mathrm{H}_{5}\right) \mathrm{Fe}^{+}$by Methyl Halides in the Gas Phase. Inorg. Chem. 1978, 17, 68-70.

10. Drewello, T.; Schwarz, H. Formation and detection of neutral half-sandwich complexes MC5H5 $(\mathrm{M}=\mathrm{Fe}, \mathrm{Co}, \mathrm{Ni})$ using neutralization-reionization mass spectrometry (NRMS). Int. J. Mass Spectrom. Ion Proc. 1989, 93, 177-183.

11. Stahl, D.; Beaudet, S.; Drewello, T.; Schwarz, H. Ionization Energies of the Cations of Metallocene (M(C5H5)2+), Their Half-Sandwich Complexes MC5H5+ and the Bare TransitionMetal Ions $\mathrm{M}+(\mathrm{M}=\mathrm{Fe}, \mathrm{Co}, \mathrm{Ni})$. Int. J. Mass Spectrom. Ion Proc. 1990, 101, 121-126.

12. Sodupe, M.; Bauschlicher, C. W. The bonding in $\mathrm{FeC}_{5} \mathrm{H}_{5}{ }^{+}$. Chem. Phys. Lett. 1993, 207, 19-22.

13. Bakhtiar, R.; Jacobson, D. B. Transition-Metal Mediated Heteroatom Removal by Reactions of $\mathrm{FeL}^{+}\left[\mathrm{L}=\mathrm{O}, \mathrm{C}_{4} \mathrm{H}_{6}, c-\mathrm{C}_{5} \mathrm{H}_{6}\right.$, $\left.c-\mathrm{C}_{5} \mathrm{H}_{5}, \mathrm{C}_{6} \mathrm{H}_{6}, \mathrm{C}_{5} \mathrm{H}_{4}\left(=\mathrm{CH}_{2}\right)\right]$ with Furan, Thiophene, and Pyrrole in the Gas Phase. J. Am. Soc. Mass Spectrom. 1996, 7, 938-952.

14. Baranov, V. I. Analytical approach for description of an ion motion in quadrupole mass spectrometry. J. Am. Soc. Mass Spectrom. 2003, 14, 818-824.

15. Baranov, V. I. Ion energy in quadrupole mass spectrometry. J. Am. Soc. Mass Spectrom. 2004, 15, 48-54.

16. Baranov, V. I.; Bohme, D. K. Coordination chemistry of $\left(\mathrm{C}-\mathrm{C}_{5} \mathrm{H}_{5}\right) \mathrm{Fe}^{+}$in the gas phase at $294+/-3 \mathrm{~K}$ : reactions with the inorganic ligands $\mathrm{H}_{-2}, \mathrm{H}_{2} \mathrm{O}, \mathrm{NH}_{3}, \mathrm{CO}, \mathrm{N}_{-2}, \mathrm{NO}, \mathrm{CO}_{2}, \mathrm{~N}_{2} \mathrm{O}$, and $\mathrm{NO}_{2}$. Int. J. Mass Spectrom. 2001, 204, 209-221.

17. Innorta, G.; Pontoni, L.; Torroni, S. Gas phase reactions of the ion $\mathrm{C}_{5} \mathrm{H}_{5} \mathrm{Fe}^{+}$: A kinetic study. J. Am. Soc. Mass Spectrom. 1998, 9, 314-319.

18. Baranov, V. I.; Tanner, S. D. A dynamic reaction cell for inductively coupled plasma mass spectrometry (ICP-DRCMS). I. The RF-field energy contribution in thermodynamics of ion-molecule reactions. J. Anal. At. Spectrom. 1999, 14, 11331142.

19. Douglas, D. J.; French, J. B. Collisional focusing effects in radio frequency quadrupoles. J. Am. Soc. Mass Spectrom. 1992, 3, $398-408$.

20. Douglas, D. J. Application of collision dynamics in quadrupole mass spectrometry. J. Am. Soc. Mass Spectrom. 1998, 9, 101-113.

21. McLuckey, S. A.; Goeringer, D. E. Slow heating methods in tandem mass spectrometry. J. Mass Spectrometry. 1997, 32, 461-474.

22. Lock, C. M.; Dyer, E. Characterization of high pressure quadrupole collision cells possessing direct current axial fields. Rapid Commun. Mass Spectrom. 1999, 13, 432-448.

23. McDaniel, E. W. Collision phenomena in ionized gases, Wiley: New York, 1964.

24. Jugroot, M.; Clinton, C. P.T.; Thompson, B. A.; Baranov, V. I.; Collings, B. A. Numerical investigation of interface region flows in mass spectrometers: ion transport. J. Phys. D: Appl. Phys. 2004, 37, 550-559.

25. Tanner, S. D. Experimental studies of ion kinetic energies in ICP-MS. In Appliction of Plasma Source Mass Spectrometry II, The Royal Society of Chemistry: Cambridge, 1993; pp 222-234.

26. Koyanagi, G. K.; Lavrov, V. V.; Baranov, V.; Bandura, D.; Tanner, S. D.; McLaren, J. W.; Bohme, D. K. A novel ICP/SIFT mass spectrometer for the study of reactions of atomic and atomic oxide ions. Int. J. Mass Spectrom. 2000, 194, L1-L5. 
27. Tanner, S. D.; Baranov, V. I. Theory, design and operation of a dynamic reaction cell for ICP- MS. At. Spectroscopy. 1999, 20, 45-52.

28. Bandura, D. R.; Baranov, V. I.; Tanner, S. D. Inductively coupled plasma mass spectrometer with axial field in a quadrupole reaction cell. J. Am. Soc. Mass Spectrom. 2002, 13, 1176-1185.

29. Tanner, S. D.; Baranov, V. I.; Bandura, D. R. Reaction cells and collision cells for ICP-MS: a tutorial review. Spectrochim. Acta Pt. B At. Spec. 2002, 57, 1361-1452.

30. Voo, A. C. C.; Ng, R.; Tunstall, J. J.; Taylor, S. Transmission through the quadrupole mass spectrometer mass filter: The effect of aperture and harmonics. J. Vac. Sci. Technol. A. 1997, 15, 2276-2281.
31. Muntean, F.; Ursu, D.; Lupsa, N. Ion trajectory analysis for rf-only quadrupoles. Vacuum 1995, 46, 131-137.

32. Muntean, F. Transmission study for rf-only quadrupoles by computer simulation. Int. J. Mass Spectrom. Ion Proc. 1995, 151, 197-206.

33. Loboda, A.; Krutchinsky, A.; Loboda, O.; McNabb, J.; Spicer, V.; Ens, W.; Standing, K. Novel Linac II electrode geometry for creating an axial field in a multipole ion guide. Eur. J. Mass Spectrom. 2000, 6, 531-536.

34. Innorta, G.; Torroni, S.; Maranzana, A.; Tonachini, G. Entropy effects in gas phase ion-molecule association reactions. J. Organomet. Chem. 2001, 626, 24-31. 